\section{In Vivo Accuracy of Two Electronic Foramen Locators Based on Different Operation Systems}

Bruno Carvalho de Vasconcelos ${ }^{1}$, Rebeca Bastos Rocha Araújo랄 Francisco Cláudio Fernandes Alves e Silva'2, Suyane Maria Luna-Cruz' ${ }^{1}$ Marco Antonio Hungaro Duarte ${ }^{3}$, Carlos Augusto de Oliveira Fernandes ${ }^{2}$
'School of Dentistry of Sobral, UFC - Federal University of Ceará, Sobral, CE, Brazil ${ }^{2} \mathrm{School}$ of Pharmacy, Dentistry and Nursing, UFC - Federal University of Ceará, Fortaleza, CE, Brazil ${ }^{3}$ Bauru School of Dentistry, USP - University of São Paulo, Bauru, SP, Brazil

Correspondence: Prof. Dr. Marco Antonio Hungaro Duarte, Al. Dr. Octávio Pinheiro Brisolla, 9-75, 17012-901 Bauru, SP, Brasil. Tel: +55-14-3235-8344. e-mail: mhungaro@travelnet. com.br; mhungaro@fob.usp.br

Key Words: electronic apex locator, root canal length determination, apical foramen, Root ZX, Propex II.

\section{Introduction}

Success of endodontic treatment may be confirmed clinically, radiographically, or histologically. Nevertheless, histological success is the true objective of endodontic therapy (1), despite not being regularly confirmed in clinical settings. Several in vivo studies demonstrated that histological conditions are more favorable when the filling remains short of or limited to the apical constriction (2). However, precise determination of this anatomical landmark is extremely difficult (3-5).

Several devices for measuring the root canal length have been developed and tested (4). Despite initially frustrating attempts, electronic foramen locators (EFLs) have evolved and today are regarded as important tools in clinical endodontic practice and currently used in several clinical conditions (5-7). Since their introduction, the precision of these devices was the aim of several ex vivo and in vivo investigations, demonstrating accuracy rates between 60\% and 100\% (3,5,7-17). Despite these high percentages, new mathematical methods for electronic canal length determination have been studied, aiming to further enhance the accuracy of the readings and minimize the potential interference of clinical factors, such as the presence of different fluids within the canal, anatomical variations, absence of foraminal patency, use in immature teeth with open apices, among others $(4,6,12)$.

Root ZX (J. Morita, Tokyo, Japan), one of the most extensively evaluated EFLs $(7,11,18,19)$, was developed in 1991 and introduced to use in 1994 (4). Its measurements are performed by calculating the impedance quotient of two distinct frequencies $(0.4$ and $8.0 \mathrm{kHz})(4,7,10,17-19)$ employed simultaneously at each point within the root canals during measurement $(4,17)$. This device has shown precision rates greater than $90 \%$ and up to $100 \%$, even when used in unfavorable conditions, and for this reason it is recognized as the gold standard for foramen locators $(5,7,12,14,18-20)$.

Propex II (Dentsply-Maillefer, Ballaigues, Switzerland), an EFL recently launched to the market, operates by capturing the signals of two alternating currents ( 0.5 and $8.0 \mathrm{kHz}$ ) and for this calculation, the mean square root of impedances at these two frequencies are measured separately. The data obtained by these calculations are compared to reference values stored in its memory, providing readings of the file positions during its penetration in the root canals $(13,15,21)$. Unlike most EFLs, the Propex II operating system measures not only the amplitude of the signal, but also its energy, being reportedly less affected 
by potential interferences in the root canal $(13,15,21)$. Previous ex vivo studies, assessing its precision at the apical foramen level, demonstrated its potential as a root canal length measurement device $(13,15,21)$.

Considering the aforementioned factors, the lack of in vivo studies evaluating the precision of EFLs that work based on analysis of signal energy, the promising accurate results of these devices, and their widespread use among endodontists, the aim of the present study was to evaluate in vivo the accuracy of Propex II in comparison with Root ZX under clinical conditions for determining apical foramen location in the same sample of teeth.

\section{Material and Methods}

Ten healthy patients aged 18 to 30 years (mean age $=$ 24 years) needing premolar extractions due to orthodontic reasons were invited to participate in the study. All participants signed an informed consent form after approval of the research protocol by the Ethics Committee of the Federal University of Ceará, Brazil (protocol \#100/11).

The inclusion criteria were: absence of systemic diseases, recommended extraction of at least one premolar as part of the orthodontic treatment planning, and vital pulp. Teeth with extensive carious lesions, metallic class II restorations or restorations with signs of leakage, presence of dental resorption, or incompletely formed apices were not included.

Seventeen permanent teeth, totaling 28 canals were used in the analyses. All clinical procedures and measurements were carried out by a single experienced operator, following the protocol described by Welk et al. (8) After the periapical radiographs were taken, the teeth were anesthetized with 2\% mepivacaine (Scandicaine 2\%; Septodont, Saint-Mar-des-Fosses, France) and isolated with a rubber dam. Access cavities were prepared using \# 1012 and \#3081 high-speed diamond burs (KG Sorensen, Barueri, SP, Brazil), under constant irrigation. Flat surfaces were created to provide stable reference points for the measurements. Canals were preflared with SX and S1 ProTaper rotary files (Dentsply-Maillefer) attached to an electric handpiece (Endomate DT; NSK, Tochigi, Japan) to 5.0 $\mathrm{mm}$ short of the total length based on the initial radiograph. Canals were irrigated during the chemomechanical preparation with 2.5\% sodium hypochlorite (Biodinâmica, Ibiporã, PR, Brazil), and at its conclusion, excess solution was aspirated, whilst keeping the canals moist.

Electronic measurements were conducted using hand $\mathrm{K}$-files (Dentsply-Maillefer) fitted to the anatomical diameter of each canal. The largest file was inserted until the tip reached the apex in the devices. Since the measurements were performed with both EFLs in all teeth, the first one to be used was randomly selected and their use was alternated. Both devices were operated according to the manufacturers' instructions: after positioning the lip clip, the electrode was attached to the file and inserted in the canal. The file was then advanced into the canal until the EFL screen displayed the word "APEX" (in Root ZX) or "APEX" simultaneously with "0.0" (in Propex II). Measurements were considered as accurate if the instrument remained stable for at least $5 \mathrm{~s}$. The rubber stop was then positioned on the occlusal reference, and a new measurement was made, with special care to avoid shifting the file. The distance between the tip of the file and the stop was measured with a digital caliper a with $\pm 0.01 \mathrm{~mm}$ resolution (FNCL; Worker, Esteio, RS, Brazil). Measurements were recorded and the procedure was repeated with the other EFL, using the same file. Next, the file was re-inserted in the canal, up to the measurement indicated by the last device and fixed in this position with a cyanoacrylate-based adhesive (Super Bonder; Loctite do
Data are shown as number (percentage). $\chi^{2}=65.062, p<0.001 .{ }^{*}$ More than one answer was possible for each response. 
Brazil, São Paulo, SP, Brazil). After the adhesive was set, the canal length measurements were confirmed, the rubber dam was removed, and the tooth was extracted.

In order to expose the canal, the apical $4.0 \mathrm{~mm}$ of each root was ground from buccal to lingual, under 16x magnification using an operating microscope (DF Vasconcellos, São Paulo, SP, Brazil). To prevent disruption of the file, the last layer was carved with a scalpel. With the aid of the microscope (20x), each specimen was photographed and the images were stored for further analysis. The distance between the tip of each file and the apical foramen was determined with the Image Tools 3.0 software (UTHSCSA, San Antonio, TX, USA), by two previously calibrated examiners who were blinded to the used device. In case of disagreement, a third examiner was consulted. Negative and positive values were attributed to measurements that were short and beyond the apical foramen, respectively. In order to prevent biased interpretation, the most coronal border of the major foramen was used as an anatomical reference for this evaluation. The difference in length $(\mathrm{mm})$ between the file that was fixed (measurement with the last $\mathrm{EFL}$ ) and the first file used (first EFL) was also calculated for

\section{Results}

Two roots fractured during extraction and two were damaged during preparation, reducing the number of canals from 28 to 24. Table 1 presents the mean distance from the tip of the instrument to the apical foramen, considering absolute values, for Root ZX $(0.30 \pm 0.29 \mathrm{~mm})$ and Propex II $(0.32 \pm 0.27 \mathrm{~mm})$. Paired statistical analysis revealed no significant differences between the devices with respect to the accuracy of apical foramen location ( $p=0.587$ ).

The distribution of the measurements obtained from both EFLs is shown in Table 2. Root ZX had precision rates ranging from $75 \%$ to $100 \%$, while the precision of Propex II ranged from $66.7 \%$ to $100 \%$, with tolerance intervals set at $\pm 0.5 \mathrm{~mm}$ and $\pm 1.0 \mathrm{~mm}$, respectively. The analyses performed by the chi-squared test did not show statistical differences. The percentages of measurements beyond the apex were 37.5\% for Root ZX and 20.9\% for Propex II.

\section{Discussion}

Despite the fact that in vitro and ex vivo results cannot be directly extrapolated to the clinical settings, these studies serve as valuable tools for assessing the precision

of EFLs $(7-9,14,20,21)$. In fact, in vivo studies, in addition to providing normal clinical conditions, also determine directly the relationship between the tip of the instruments and the apical anatomical structures, therefore being an efficient and precise evaluation method $(8,9,14,21)$.

The present work evaluated the precision of two EFLs for establishing the location of the apical foramen, while attempting to minimize anatomical or external interferences. For this reason, only teeth with vital pulps $(3,22)$, subjected to coronal preflaring $(11,23,24)$, and with patent apical foramina $(5,20)$ were included in the study. In order to further limit potential interferences, the used files were well fitted to the diameter of each canal $(6,11)$ and $2.5 \%$ sodium hypochlorite was the only irrigating solution $(5,7,11,17,18)$. Moreover, both EFLs were used alternately in all root canals to ensure absolutely similar clinical conditions, as reported elsewhere $(8,9)$.

The anatomical structure that should be used as an apical reference for the calculations of EFL error is not completely defined among different researchers. Some recommend using the apical constriction $(8,9,15,20)$, while others prefer the apical foramen $(7,12,14)$. Many authors have suggested that determining the accurate location of the apical constriction is extremely difficult, almost impossible in some cases $(12,14,18)$, therefore the use of the apical foramen as a reference for the measurements, as described above (14).

The precision rates presented by Root ZX in this study were $75 \%( \pm 0.5 \mathrm{~mm})$ and $100 \%( \pm 1.0 \mathrm{~mm})$, with a mean discrepancy of $0.30 \mathrm{~mm}$ from the apical foramen. These results corroborate findings by other authors, who observed percentages ranging from $60 \%$ to $100 \%$, depending on the tolerance margin, and mean error values near $0.0 \mathrm{~mm}$ (7$11,20)$. These values certify the efficiency of the Root $Z X$ measurement approach, confirming that the evaluation of the quotient of impedances of two frequencies measured simultaneously may be considered a strongly reliable method. Measurements beyond the foramen occurred in $37.5 \%$ of the measurements, which agrees with other authors who reported $40 \%$ (9) and $25.0 \%$ (5). However, the occurrence of measurements beyond the foramen could be due to a greater proximity to this anatomical reference. These occurrences make up for only $12.5 \%$ of the cases if only measurements beyond the apex with distance greater than the tolerance margin were considered.

Precision of $66.7 \%( \pm 0.5 \mathrm{~mm})$ and $100 \%( \pm 1.0 \mathrm{~mm})$ was observed for Propex II with a mean distance of $0.32 \mathrm{~mm}$ from the apical foramen. These results were in agreement with another in vivo study performed by Somma et al. (25) who reported a precision rate of $100 \%( \pm 0.5 \mathrm{~mm})$ with a mean discrepancy of $0.14 \mathrm{~mm}$, using also the major foramen as apical reference. This small difference can be explained 
by slight variations in experimental design, as the number of specimens and the evaluation method. Other previous ex vivo studies show a precision of $82.2 \%( \pm 0.5 \mathrm{~mm})$, with a mean discrepancy of $0.27 \mathrm{~mm}$ (13) and a precision of $89.7 \%( \pm 0.5 \mathrm{~mm})$ with a mean discrepancy of $0.14 \mathrm{~mm}(15)$. Comparisons of these results with those from the present study reveal that while the discrepancy values were similar, the in vivo precision rates of Propex II were lower. Such differences may be attributed to factors inherent to these ex vivo studies, such as the use of an electroconductive gel to simulate the periodontal tissues. The percentage of measurements beyond the MF for Propex II (20.7\%) was lower than that of Root $Z X$, which agrees with reports from previous ex vivo studies, where measurements beyond the apical foramen accounted for $17.8 \%(15,18)$.

Unquestionably the inclusion of EFLs in the arsenal of clinicians and endodontists reflects an increase of treatment quality, mainly with regards to the determination of the root canal length, often confused by the radiographic interpretation $(3,4)$. However, while using them it is important to reach the apical foramen as a means to provide the electronic devices with all the information (capacitance) resistance) of the root canal system (4). To achieve this goal, the best reference is to reach "APEX" or " 0.0 " on the device display. Nevertheless, the results presented here corroborate those of numerous other studies that state that the EFLs cannot exactly detect the foraminal position $(3,8,9,12,20)$, but they can indicate a point located between the apical constriction and the major foramen. Thus, the "APEX" presented by the devices should not be interpreted by the clinicians as literally the foraminal position, but a reference only, as advised by Haffner et al. (3).

Considering the tested devices, the absence of statistically significant differences between Propex II and Root ZX measurements suggests that the operating mechanism of the novel EFL, which is based on evaluating the energy of the current signal by calculating the mean square root of impedances in two frequencies, seems to be reliable. This device was capable of exceeding interferences in the resistance/capacitance system, since its mean error was close to the apical foramen and similar to the gold standard device. Moreover, this system demonstrated to be safe, since the percentage of measurements beyond the apical foramen with distances greater than the tolerance margin was only $4.2 \%$.

Under the conditions of this in vivo study, Root ZX and Propex II were capable of locating the apical foramen region with high precision suggesting, despite their operating modes, they can surpass the difficulties in determining the root canal length and could be confirmed as reliable tools. The present data revealed no differences in accuracy between the EFLs. Although Root ZX presented a higher percentage of readings beyond the apex, the differences were not significant when statistically compared.

\section{Resumo}

0 presente estudo teve como objetivo avaliar, in vivo, a precisão de dois localizadores eletrônicos foraminais (LEFs) baseados em diferentes mecanismos de funcionamento, Root ZX e Propex II, na determinação do forame apical, sendo utilizados nos mesmos dentes. Após o acesso coronário e o pré-alargamento, e anteriormente à exodontia, os comprimentos de 24 canais radiculares foram determinados eletronicamente alternando-se os dois LEFs. As odontometrias foram realizadas até que os dispositivos apontassem o FA (APEX), utilizando-se limas tipo-K ajustadas. 0 último instrumento utilizado foi fixado em posição, o dente extraído e os $4,0 \mathrm{~mm}$ apicais de cada canal desgastados de forma a possibilitar a determinação da distância entre a ponta dos instrumentos e o forame apical. Os erros médios em função dos valores absolutos das discrepâncias foram, respectivamente, $0,30 \pm 0,29 \mathrm{~mm}(\operatorname{Root} Z X)$ e 0,32 $\pm 0,27 \mathrm{~mm}$ (Propex II). A análise estatística realizada por meio do teste de Wilcoxon para amostras pareadas demonstrou a semelhança entre as determinações do forame apical realizadas pelos dois LEFs $(p=0,587)$. 0 comprimento radicular até o forame apical foi corretamente determinado em 75\% (Root ZX) e 66,7\% (Propex II) dos casos, considerando margem de $\pm 0,5 \mathrm{~mm}$, sem diferenças estatísticas quando analisados pelo teste qui-quadrado. Os LEFs avaliados e consequentemente seus mecanismos de funcionamento, foram capazes de determinar o comprimento dos canais radiculares com precisão em condições in vivo. Nas condições do presente estudo, Root ZX e Propex II apresentaram resultados semelhantes.

\section{References}

1. Wu MK, Shemesh H, Wessellink PR. Limitations of previously published systematic reviews evaluating the outcome of endodontic treatment. Int Endod J 2009;42:656-666.

2. Riccuci $D$, Langeland K. Apical limit of root canal instrumentation and obturation, part 2. Histological study. Int Endod J 1998;31:394-409.

3. Haffner C, Folwaczny M, Galler K, Hickel R. Accuracy of electronic apex locators in comparison to actual length - an in vivo study. J Dent 2005;33:619-625.

4. Nekoofar MH, Ghandi MM, Hayes SJ, Dummer PMH. The fundamental operating principles of electronic root canal length measurement devices. Int Endod J 2006;39:595-609.

5. Vyeira JP, Acosta J. Comparison of working length determination with radiographs and four electronic apex locators. Int Endod J 2011;44:510518.

6. Ebrahim AK, Wadachi R, Suda H. Ex vivo evaluation of the ability of four different electronic apex locators to determine the working length in teeth with various foramen diameters. Aust Endod J 2006;51:258-262.

7. Vasconcelos BC, Vale TM, Menezes AST, Pinheiro-Jr EC, Vivacqua-Gomes $N$, Bernardes RA, et al.. An ex vivo comparison of root canal length determination by three electronic apex locators at positions short of the apical foramen. Oral Surg Oral Med Oral Pathol Oral Radiol Endod 2010;110:e57-e61.

8. Welk AR, Baumgartner JC, Marshall JG. An in vivo comparison of two frequency-based electronic apex locators. J Endod 2003:29;497-500.

9. Wrbas KT, Ziegler AA, Altenburger MJ, Schirrmeister JF. In vivo comparison of working length determination with two electronic apex locators. Int Endod J 2007;40:133-138.

10. Bernardes RA, Duarte MAH, Vasconcelos BC, Moraes IG, Bernardineli $N$, Garcia $R B$, et al.. Evaluation of precision length determination with 3 electronic apex locators: Root ZX, Elements Diagnostic Unit, RomiApex D-30. Oral Surg Oral Med Oral Pathol Oral Radiol Endod 2007;104:e91-e94.

11. Camargo EJ, Zapata RO, Medeiros PL, Bramante CM, Bernardineli $\mathrm{N}$, Garcia $\mathrm{RG}$, et al.. Influence of preflaring on the accuracy of length determination with four electronic apex locators. J Endod 2009;35:1300-1302.

12. Stoll R, Urban-Klein B, Roggendorf MJ, Jablonski-Momeni A, Strauch 
K, Frankenberger R. Effectiveness of four electronic apex locators to determine distance from apical foramen. Int Endod J 2010;43:808-817.

13. Cianconi L, Angotti V, Felici R, Conte G, Mancini M. Accuracy of three electronic apex locators compared with digital radiography: an ex vivo study. J Endod 2010;36:2003-2007.

14. Stober EK, Duran-Sindreu F, Mercandé M, Vera J, Bueno R, Roig M. An evaluation of Root ZX and iPex apex locators: an in vivo study. J Endod 2011;37:608-610.

15. Mancini M, Felici R, Conti G, Constantine M, Cianconi L. Accuracy of three electronic apex locators in anterior and posterior teeth: an ex vivo study. J Endod 2011;37:684-687.

16. Paludo L, Souza SL, Só MVR, Rosa RA, Vier-Pelisser FV, Duarte MAH. An in vivo radiographic evaluation of the accuracy of Apex and iPex electronic apex locators. Braz Dent J 2012;23:54-58.

17. Vasconcelos BC, Matos LA, Pinheiro-Júnior EC, Menezes AST, VivacquaGomes N. Ex vivo accuracy of three electronic apex locators using different apical file sizes. Braz Dent J 2012;23:199-204.

18. Vasconcelos BC, Bueno MM, Luna-Cruz SM, Duarte MAH, Fernandes CAO. Accuracy of five electronic foramen locators with different operating systems: an ex vivo study. J Appl Oral Sci 2013;21:132-7.

19. Khattak 0 , Raidullah $E_{1}$ Francis ML. A comparative assessment of the accuracy of electronic apex locator (Root ZX) in the presence of commonly used irrigating solutions. J Clin Exp Dent 2014 1;6:e41-e46.
20. Plotino G, Grande NM, Brigante L, Lesti B, Somma F. Ex vivo accuracy of three electronic apex locators: Root ZX, elements diagnostic unit and apex locator and ProPex. Int Endod J 2006;39:408-414.

21. Khursheed I, Bansal R, Bansal T, Singh HP, Yadav M, Reddy KJ. A comparative evaluation of working length with digital radiography and third generation apex locator (ProPex) in the presence of various intracanal irrigants: An in vivo/ex vivo study. Dent Res J 2014;11:56-60.

22. Akisue $E$, Gavim $G$, de Figueredo JA. Influence of pulp vitality on length determination by using the Elements Diagnostic Unit and Apex Locator. Oral Surg Oral Med Oral Pathol Oral Radiol Endod 2007;104:e129-e132.

23. Ibelli GS, Barroso JM, Capelli A, Spanó JC, Pécora JD. Influence of cervical preflaring on apical file size determination in maxillary lateral incisors. Braz Dent J 2007;18:102-106.

24. Souza RA, Sousa YT, Figueiredo JA, Dantas J da C, Colombo S, Pécora JD. Influence of apical foramen lateral opening and file size on cemental canal instrumentation. Braz Dent J 2012;23:122-126.

25. Somma F, Castagnola R, Lajolo $\mathrm{C}$, Paternò Holtzman $\mathrm{L}$, Marigo L. In vivo accuracy of three electronic root canal length measurement devices: Dentaport ZX, Raypex 5 and ProPex II. Int Endod J 2012;45:552-556.

Received October 16, 2012 Accepted December 17, 2013 